\title{
CRESCIMENTO RADICULAR, EXTRAÇÃO DE NUTRIENTES E PRODUÇÃO DE GRÃOS DE GENÓTIPOS DE MILHO EM DIFERENTES QUANTIDADES DE PALHA DE AVEIA-PRETA EM PLANTIO DIRETO(1)
}

\author{
João Carlos de Moraes Sá(2), Ademir de Oliveira Ferreira ${ }^{(3)}$, Clever Briedis ${ }^{(4)}$, \\ Ângelo Marcio Vieira ${ }^{(5)} \&$ André Gradowski de Figueiredo ${ }^{(6)}$
}

\begin{abstract}
RESUMO
A manutenção da palha na superfície do solo atua principalmente na proteção contra o impacto das gotas de chuva, reduzindo a desagregação, o escorrimento superficial, o transporte de sedimentos e, consequentemente, a erosão. Essa proteção pode ter efeitos significativos nos atributos da planta de milho. $\mathrm{O}$ objetivo deste trabalho foi avaliar o efeito da quantidade de palha de aveia-preta em plantio direto no crescimento radicular, na extração de nutrientes e na produção de grãos de genótipos de milho. O experimento foi conduzido em um Latossolo Vermelho distrófico típico, em delineamento experimental de blocos ao acaso em parcelas subdivididas, com três repetições. A parcela principal foi representada pela quantidade de palha na superfície do solo (0, sem palha; 5,0; e 10,0 $\mathrm{Mg} \mathrm{ha}^{-1}$ ), e a subparcela, constituída por 13 genótipos de milho. A quantidade de palha alterou significativamente o comprimento radicular e a altura de requeima. Todavia, a interação entre palha e genótipo alterou significativamente as variáveis estudadas. $O$ sistema radicular das plantas de milho foi beneficiado por doses adicionais de palha tanto na camada superficial $(0-20 \mathrm{~cm})$ como na subsuperficial $(50-100 \mathrm{~cm})$ do solo. $\mathrm{O}$ aumento na quantidade de palha na superfície do solo resultou na maior extração total de N, P e K e não alterou a extração total dos elementos Ca, Mg e S pela planta de milho.
\end{abstract}

Termos de indexação: Zea mays, sistema radicular, resíduos culturais.

\footnotetext{
(1) Recebido para publicação em junho de 2009 e aprovado em maio de 2010.

(2) Professor Adjunto, Departamento de Solos e Engenharia Agrícola, Universidade Estadual de Ponta Grossa - UEPG. Av. Gal. Carlos Cavalcanti 4748, CEP 84030-900 Ponta Grossa (PR). E-mail: jcmsa@uepg.br

(3) M.Sc. em Agronomia, Doutorando do Programa de Pós-Graduação em Ciência do Solo, Departamento de Manejo e Conservação do Solo. Universidade Federal de Santa Maria - UFSM. Av. Roraima 1000, Camobi, CEP 97105900 Santa Maria (RS). Bolsista do CNPq. E-mail: aoferreira1@yahoo.com.br

(4) Engenheiro-Agrônomo, Mestrando do Curso de Pós-Graduação em Agronomia. E-mail: cleverbriedis@yahoo.com.br

(5) Coamo Agroindustrial Cooperativa, Rodovia BR 373, s/n, São Cristóvão, CEP 85550-000 Coronel Vivida (PR). E-mail: avieira@coamo.com.br

(6) Monsanto do Brasil Ltda., Departamento de Tecnologia, Avenida das Nações Unidas, no 12901, Torre Norte, $7^{\circ}$ andar, Brokling Paulista, CEP 04578-910 São Paulo (SP). E-mail: andre.g.figueiredo@monsanto.com
} 


\title{
SUMMARY: ROOT GROWTH, NUTRIENT EXTRACTION AND GRAIN YIELD OF CORN GENOTYPES UNDER DIFFERENT AMOUNTS OF BLACK OAT CROP RESIDUES UNDER NO-TILLAGE
}

\begin{abstract}
Crop residues on the soil surface act mainly as protection against raindrop impact, reducing aggregate disruption, runoff, sediment transport and consequently, erosion. This protection can have significant effects on the corn plant characteristics. The objective of this study was to evaluate the effect of the amount of black oat residues on no-tillage root development, nutrient uptake and grain yield of corn genotypes. The experiment was conducted in an Oxisol, in a randomized block design in split plots with three replications. The main plot was represented by the amount of black oat residues on the soil surface ( 0 , no residues, 5.0 and $10.0 \mathrm{Mg} \mathrm{ha^{-1 } )}$ and sub-plots consisting of 13 maize genotypes. The amount of crop residues affected root length significantly, at the time of leaf burning. The interaction between crop residues $x$ genotype affected the variables in this study significantly. The maize root system was stimulated by additional doses of black oat residues, both in the soil surface $(0-20 \mathrm{~cm})$ and the subsurface layer $(50-100 \mathrm{~cm})$. The increased amount of crop residue on the soil surface resulted in greater $N, P$ and $K$ uptake and did not affect the uptake of $C a, M g$ and $S$ by the corn plants.
\end{abstract}

Index terms: Zea mays, root system, crop residue.

\section{INTRODUÇÃO}

Atualmente no Brasil, a área cultivada com o sistema plantio direto (SPD) é de cerca de 25,5 milhões de hectares (Febrapdp, 2008). Inúmeros trabalhos têm constatado maior eficiência desse sistema de manejo do solo em relação ao preparo convencional na melhoria de propriedades físicas, químicas e biológicas, além do maior retorno econômico. Nas décadas de 1980 e 1990, um dos principais questionamentos na área de ciência do solo foi sobre o manejo da fertilidade, destacando-se o modo de aplicação de fertilizantes, o uso de nitrogênio e a correção da acidez do solo (Sá, 1999; Caires et al., 1999, 2000).

O avanço no conhecimento de atributos da fertilidade do solo desencadeou maiores estudos sobre o desempenho das culturas, em especial do milho, como componente-chave para a rotação de culturas no SPD (Sá, 1999). Recentemente, Sá et al. (2007) constataram que, quanto maior o tempo de adoção do sistema plantio direto, melhor a distribuição radicular da cultura de milho, mostrando maior quantidade de raízes no perfil do solo $(0-100 \mathrm{~cm})$ no plantio direto em comparação ao preparo convencional.

Do ponto de vista nutricional, a planta de milho é considerada exigente, e o suprimento de nutrientes em quantidade adequada é um ponto-chave para aumentar a produtividade dessa cultura (Fancelli \& Dourado-Neto, 2000). A quantidade de nutrientes extraídos dependerá da produtividade obtida e do acúmulo de nutrientes nos grãos e em outras partes da planta (Rodriguez, 1977; Pollmer et al., 1979). De maneira geral, as extrações de N, P, K, Ca e Mg aumentam com o acréscimo da produtividade. O N é o nutriente absorvido em maior quantidade, seguido do K, P, Ca e $\mathrm{Mg}$ (Coelho \& França, 1995; Vasconcellos et al., 1998).
Do ponto de vista da fertilidade do solo, diversos trabalhos mostraram o efeito da mineralização dos resíduos culturais no acúmulo de nutrientes na camada superficial do solo, influenciando as culturas em rotação (Sá, 1993; Sá et al., 1999; Purnomo et al., 2000; Sá et al., 2001; Aita \& Giacomini, 2003; GamaRodrigues et al., 2007; Siqueira Neto et al., 2009). Recentemente, Ferreira et al. (2009) reportaram que genótipos de milho apresentam comportamento diferenciado no aproveitamento do nitrogênio mineralizado da palha e no comprimento radicular quando submetidos a diferentes quantidades de palha de aveia-preta na superfície do solo.

A manutenção da palha na superfície do solo atua principalmente na proteção contra o impacto das gotas de chuva, reduzindo a desagregação, o escorrimento superficial, o transporte de sedimentos e, consequentemente, a erosão. Além disso, o benefício da palha pode amenizar o efeito da estiagem, reduzindo a evaporação da água e mantendo o solo úmido por um período mais prolongado (Cruz et al., 2007). Essa proteção tem efeito significativo no desenvolvimento radicular do milho (Ferreira et al., 2009).

O objetivo deste trabalho foi avaliar o desenvolvimento radicular, a extração de nutrientes e a produção de grãos de genótipos de milho quando submetidos a quantidades de palha de aveia-preta no sistema plantio direto.

\section{MATERIAL E MÉTODOS}

O experimento foi conduzido na estação experimental da Monsanto do Brasil, nos anos agrícolas de 2001/ 2002 e 2002/2003, situada na cidade de Ponta Grossa, 
região centro-sul do Estado do Paraná, cujas coordenadas geográficas de referência são: $50^{\circ} 20^{\prime} \mathrm{W}$ e $25^{\circ} 20$ ' S. A área experimental situa-se a 970 m acima do nível do mar, sob o clima subtropical úmido, mesotérmico, do tipo cfb (classificação de Köppen). A precipitação pluvial média anual e a temperatura média anual referente aos anos agrícolas do experimento foram, respectivamente, de $1.338 \mathrm{~mm} \mathrm{e} 18,7^{\circ} \mathrm{C}$. $\mathrm{O}$ relevo caracteriza-se como suave ondulado, com pendentes entre 2 e $7 \mathrm{~cm} \mathrm{~m}^{-1}$ de declividade.

O material de origem é constituído por sedimentos clásticos do período Devoniano, caracterizados por materiais retrabalhados de arenitos da formação Furnas e folhelhos da formação Ponta Grossa. O solo foi classificado como Latossolo Vermelho distrófico típico (Embrapa, 2006). Esses solos apresentam baixa fertilidade natural e possuem elevado conteúdo de $\mathrm{Al}$ trocável.

Antes do início da exploração agrícola, a área encontrava-se sob a vegetação natural, denominada de "Campos Nativos". Na década de 1980 iniciou-se a conversão desses campos em áreas de cultivo, e durante os primeiros 12 anos as culturas de trigo e soja foram cultivadas em sucessão sob o sistema de preparo convencional. Nos últimos seis anos foi adotado o SPD, com a rotação de culturas - aveia-preta - soja/ trigo - soja/aveia-preta - milho.

O delineamento experimental foi constituído em blocos ao acaso com arranjo em parcelas subdivididas, com três repetições. A parcela foi representada pela quantidade de resíduos culturais de aveia-preta (Avena strigosa) - denominado de palha, mantidos na superfície do solo: 0, 5,0 e 10,0 $\mathrm{Mg} \mathrm{ha}^{-1}$. A subparcela foi constituída por 13 genótipos de milho: DKB 212, DKB 214, DKB 215, AG 6018, AG 9020, DKB 350, DKB 747, MTC 907, MTC 955, DKB 909, EX 1104, EX 3308 e EX 1108. A parcela com 5,0 $\mathrm{Mg} \mathrm{ha}^{-1}$ representa a quantidade de palha (parte aérea) obtida em todo o talhão e calculada pela média de 10 pontos de amostragem no momento da instalação do experimento para determinação da matéria seca. A parcela sem palha foi constituída a partir da remoção de toda a palha que estava na superfície após o corte das plantas rente ao solo. Utilizou-se um rastelo de hastes de aço flexível para remover a palha, evitando o revolvimento e a alteração da estrutura do solo da camada superficial. A parcela com $10,0 \mathrm{Mg} \mathrm{ha}^{-1}$ foi obtida transferindo-se a palha removida $\left(5,0 \mathrm{Mg} \mathrm{ha}^{-1}\right)$ da parcela denominada sem palha para a parcela com $5,0 \mathrm{Mg}$ ha $^{-1}$. Tanto a retirada quanto a colocação de palha nas parcelas ocorreram após a rolagem da aveiapreta no ano agrícola do experimento e perduraram por quase todo o ciclo da cultura do milho, ou seja, até o florescimento pleno. A dimensão das parcelas era de $10,0 \times 41,6 \mathrm{~m}$, e das subparcelas, de $10,0 \mathrm{~m}$ de comprimento e seis linhas para cada genótipo. A distribuição e uniformização da palha na parcela foi realizada 10 dias após a aplicação do herbicida glifosate na dose de 2,0 $\mathrm{L} \mathrm{ha}^{-1}$, para dessecação da cobertura vegetal. O intervalo entre a dessecação e a semeadura de milho foi de 30 dias.

A semeadura foi realizada manualmente com auxílio de matracas, colocando duas sementes por cova nos sulcos espaçados de 0,80 m entre si e abertos por uma semeadora. A adubação no sulco foi com $360 \mathrm{~kg} \mathrm{ha}^{-1}$ da fórmula NPK 10-20-20 + 1\% Zn. Após a semeadura foi aplicada nova dose de glifosate, para o controle de ervas remanescentes da dessecação da cultura de aveia-preta. A profundidade de deposição do fertilizante foi ao redor de $12 \mathrm{~cm}$, e a profundidade de semeadura, de 4 a $5 \mathrm{~cm}$. Aos 15 dias após a emergência foi realizado o desbaste, eliminando uma das plantas para manter a população final de 57.500 plantas ha-1. A adubação nitrogenada de cobertura foi realizada nos estádios $\mathrm{V}_{2} \mathrm{eV}_{6}$, utilizandose 150 e $100 \mathrm{~kg} \mathrm{ha}^{-1}$ de ureia, respectivamente. A quantidade total de $\mathrm{N}$ aplicado (sulco de semeadura + cobertura) foi de $148,5 \mathrm{~kg} \mathrm{ha}^{-1}$, quantidade esta acima da recomendada para a cultura do milho, mas que nesse caso serviu para amenizar o efeito da palha no comportamento dos genótipos em relação à imobilização do nitrogênio durante sua decomposição. $\mathrm{O}$ controle das plantas daninhas foi feito com o uso de herbicidas do grupo químico atrazina.

No estádio de florescimento pleno foram coletadas amostras de solo nas trincheiras escavadas, para avaliação do sistema radicular. A coleta foi realizada em 10 trincheiras por bloco, para constituir uma amostra composta nas profundidades: $0-10,10-20$, 20-30, 30-40, 40-50, 50-60, 60-70, 70-80, 80-90 e 90-100 cm (Quadro 1). A análise química foi realizada de acordo com Pavan et al. (1991); a granulométrica, pelo método de Bouyoucos conforme descrito por Embrapa (1997); P (Mehlich-1); e C-orgânico (WalkleyBlack).

A quantificação do comprimento radicular no perfil do solo foi feita por meio do software SIARCS 3.0, desenvolvido pela Embrapa e reportado por Crestana et al. (1994). Trincheiras medindo 1,10 m de largura e 1,30 m de profundidade foram escavadas no sentido perpendicular à linha central de cada unidade experimental e a $10 \mathrm{~cm}$ de distância do colmo do milho, em estádio de florescimento pleno. A face da trincheira utilizada na avaliação das raízes foi centrada na linha da planta e escarificada manualmente $\mathrm{em} \pm 1$ a $2 \mathrm{~cm}$, para expor o sistema radicular. Um quadro de madeira com $0,80 \mathrm{~m}$ de largura e $1,0 \mathrm{~m}$ de profundidade, dividido em quadrículas por fios de náilon de $0,10 \times 0,10 \mathrm{~m}$, foi colocado na face escarificada da trincheira, e as imagens das raízes foram obtidas com auxílio de uma câmera fotográfica digital.

A coleta de plantas para avaliação da matéria seca e extração de macronutrientes foi realizada na maturidade fisiológica, coletando-se duas plantas por unidade experimental, as quais foram subdivididas em três partes (folha, colmo e espiga). 
Quadro 1. Resultados da análise química e física do solo em amostras coletadas em trincheiras escavadas nas subparcelas no estádio de florescimento pleno dos híbridos de milho (média dos anos agrícolas 2001/2002 e 2002/2003)

\begin{tabular}{|c|c|c|c|c|c|c|c|c|c|c|c|c|c|c|}
\hline Profundidade & pH $\mathrm{CaCl}_{2}$ & $\mathrm{CO}$ & P Mehlich-1 & Al & $\mathbf{H}+\mathbf{A l}$ & $\mathbf{C a}$ & Mg & $\mathbf{K}$ & CTC & $\mathbf{V}$ & $\mathbf{m}$ & Areia & Silte & Argila \\
\hline $\mathrm{cm}$ & & $\mathrm{g} \mathrm{dm}^{-3}$ & $\mathrm{mg} \mathrm{dm}^{-3}$ & & 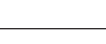 & $-\mathrm{cmc}$ & $c \mathrm{dm}^{-3}$ & & & 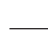 & 6 & 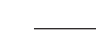 & $-\mathrm{g} \mathrm{kg}^{-1}$ & 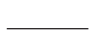 \\
\hline $0-10$ & 5,0 & 25,0 & 2,8 & 0,1 & 7,1 & 4,3 & 2,9 & 0,2 & 14,4 & 51 & 0,7 & 390 & 197 & 413 \\
\hline $10-20$ & 4,6 & 20,0 & 1,7 & 0,4 & 8,7 & 2,2 & 1,8 & 0,2 & 12,8 & 32 & 8,9 & 397 & 210 & 393 \\
\hline $20-30$ & 4,3 & 13,5 & 1,1 & 0,8 & 9,7 & 0,7 & 1,3 & 0,1 & 11,8 & 18 & 27 & 373 & 214 & 413 \\
\hline $30-40$ & 4,4 & 12,5 & 1,1 & 0,5 & 8,7 & 0,9 & 1,1 & 0,1 & 10,7 & 19 & 20 & 344 & 216 & 440 \\
\hline $40-50$ & 4,6 & 14,5 & 1,2 & 0,4 & 7,8 & 1,2 & 1,2 & 0,1 & 10,2 & 24 & 14 & 328 & 215 & 457 \\
\hline $50-60$ & 4,7 & 15,0 & 1,3 & 0,3 & 7,1 & 1,3 & 1,3 & 0,1 & 9,7 & 27 & 10 & 322 & 215 & 463 \\
\hline $60-70$ & 4,7 & 10,0 & 1,3 & 0,3 & 6,9 & 1,2 & 1,1 & 0,1 & 9,2 & 25 & 9,8 & 320 & 217 & 463 \\
\hline $70-80$ & 4,7 & 8,5 & 1,3 & 0,2 & 6,5 & 0,9 & 1,0 & 0,0 & 8,3 & 22 & 7,3 & 309 & 201 & 490 \\
\hline $80-90$ & 5,0 & 7,0 & 1,4 & 0,0 & 5,4 & 0,8 & 0,9 & 0,0 & 7,1 & 24 & 0,0 & 312 & 218 & 470 \\
\hline $90-100$ & 5,0 & 7,0 & 1,4 & 0,0 & 5,2 & 0,8 & 1,1 & 0,0 & 7,0 & 27 & 0,0 & 313 & 227 & 460 \\
\hline
\end{tabular}

Na coleta das plantas, tomou-se cuidado para manter o material livre de impurezas oriundas do campo, principalmente solo, pois essas mesmas plantas foram utilizadas na determinação de macronutrientes dos tecidos, após a obtenção da matéria seca. Antes da colocação na estufa para secagem, as plantas foram lavadas com água deionizada, procurando retirar a poeira do material, evitando com isso interferência nos resultados de extração de macronutrientes. As plantas, após a lavagem, ficaram secando à sombra por aproximadamente $24 \mathrm{~h}$, em sala ventilada.

Após esse período de pré-secagem, para eliminação da umidade mais grosseira, as plantas (subdivididas) foram acondicionadas em estufa de circulação de ar, ajustada para a temperatura de $64{ }^{\circ} \mathrm{C}$, até obtenção do peso constante (aproximadamente $72 \mathrm{~h}$ ). Em seguida, foi realizada a pesagem em balança digital.

O material foi moído em triturador específico, para preparação de materiais para extração de nutrientes. Desse material triturado, devidamente separado em folha, colmo e espiga, foram retiradas as amostras para encaminhamento ao laboratório, para determinação dos macronutrientes dos tecidos. As análises foram feitas pelo Laboratório de Análise Foliar do Departamento de Solos e Nutrição de Plantas ESALQ/USP.

Segundo Malavolta et al. (1997), foram determinados o N, P, K, Ca, Mg e S no tecido de folhas, colmos e grãos (a palha da espiga mais o sabugo não foram trituradas para quantificação de sua composição, porém suas matérias secas foram consideradas no valor da matéria seca do colmo). A extração total foi baseada na concentração do elemento no tecido vegetal e convertida em $\mathrm{kg} \mathrm{ha}^{-1}$, em função da matéria seca de cada componente (folha, colmo e espiga).

Os resultados foram submetidos à análise de variância pelo programa SISVAR 5.0, utilizando o teste de Tukey a $5 \%$. Para obtenção das curvas de resposta, foi utilizado o procedimento da análise de regressão pelo programa JMP IN® version 3.2.1 (Sall et al., 2005), empregado o teste $\mathrm{F}$ a 5,1 e $0,1 \%$.

\section{RESULTADOS E DISCUSSÃO}

\section{Influência da quantidade de palha na superfície do solo em atributos da planta de milho}

As variáveis comprimento radicular, produtividade e extração de N, P, K, Mg e S apresentaram interação significativa entre quantidade de palha e genótipo (Quadro 2).

Conforme Cruz et al. (2007), a manutenção da palha na superfície do solo atua principalmente na proteção contra o impacto das gotas de chuva, reduzindo a desagregação, o escorrimento superficial, o transporte de sedimentos e, consequentemente, a erosão. Além disso, atua na proteção do solo contra o efeito dos raios solares, reduzindo a evaporação, a temperatura e a amplitude térmica do solo, contra a ação de ventos e auxilia no controle de plantas daninhas, pela supressão ou efeito alelopático. Neste estudo, o benefício da palha foi amenizar o efeito da estiagem que ocorreu entre os estádios V3 e V4, reduzindo a evaporação da água e mantendo o solo úmido por um período mais prolongado. Essa proteção teve efeito significativo no desenvolvimento radicular do milho (Figura 1), com aumento no comprimento radicular tanto na camada superficial como em profundidade no perfil. Na camada superficial de $0-10 \mathrm{~cm}$, a resposta do sistema radicular à quantidade de palha foi linear, e o ganho médio foi de 22 até $42 \%$ em favor dos tratamentos com 5,0 e 10,0 $\mathrm{Mg} \mathrm{ha}^{-1}$ de palha de aveia-preta, respectivamente (Figura 1). 
Quadro 2. Análise de variância do comprimento radicular $\left(\mathrm{m} \mathrm{m}^{-2}\right)$, produtividade $\left(\mathrm{kg} \mathrm{ha}^{-1}\right)$ e extração total (folha + colmo + espiga) de nutrientes $\left(\mathrm{kg} \mathrm{ha}^{-1}\right)$ em razão da quantidade de palha e dos genótipos em um Latossolo Vermelho distrófico, após seis anos de plantio direto

\begin{tabular}{|c|c|c|c|c|c|c|c|c|}
\hline \multirow{2}{*}{ Causas de variação } & \multirow{2}{*}{ Raiz } & \multirow{2}{*}{ Produtividade } & \multicolumn{6}{|c|}{ Nutrientes } \\
\hline & & & $\mathbf{N}$ & $\mathbf{P}$ & $\mathbf{K}$ & $\mathbf{C a}$ & Mg & $\mathbf{S}$ \\
\hline Quantidade de palha & & $\mathrm{ns}$ & * & * & * & $\mathrm{ns}$ & * & * \\
\hline CV (\%) & 16,32 & 13,40 & 5,20 & 2,40 & 8,15 & 14,06 & 10,24 & 4,60 \\
\hline Genótipo & ns & * & * & * & $\mathrm{ns}$ & * & * & * \\
\hline Quantidade de palha $\mathrm{x}$ genótipo & & * & * & * & * & * & * & * \\
\hline CV (\%) & 26,26 & 13,40 & 9,17 & 2,73 & 23,70 & 14,40 & 10,83 & 4,99 \\
\hline
\end{tabular}

ns: não significativo, ${ }^{*}$ : significativo a $5 \%$.

Esses resultados contrastam com os verificados por Ferreira et al. (2009), que não obtiveram resposta significativa na resposta do sistema radicular à quantidade de palha. Esse contraste está provavelmente relacionado com o tempo de duração do plantio direto (18 anos) na situação reportada por esses autores. Neste estudo, a área experimental encontrava-se com seis anos sob o SPD e, de acordo com Sá et al. (2004), nessa situação o plantio direto encontra-se na fase inicial (6 anos), na qual o baixo acúmulo de palha, o restabelecimento da biomassa microbiana, a maior exigência de $\mathrm{N}$ e o rearranjo da estrutura do solo são as principais características. Por outro lado, na fase

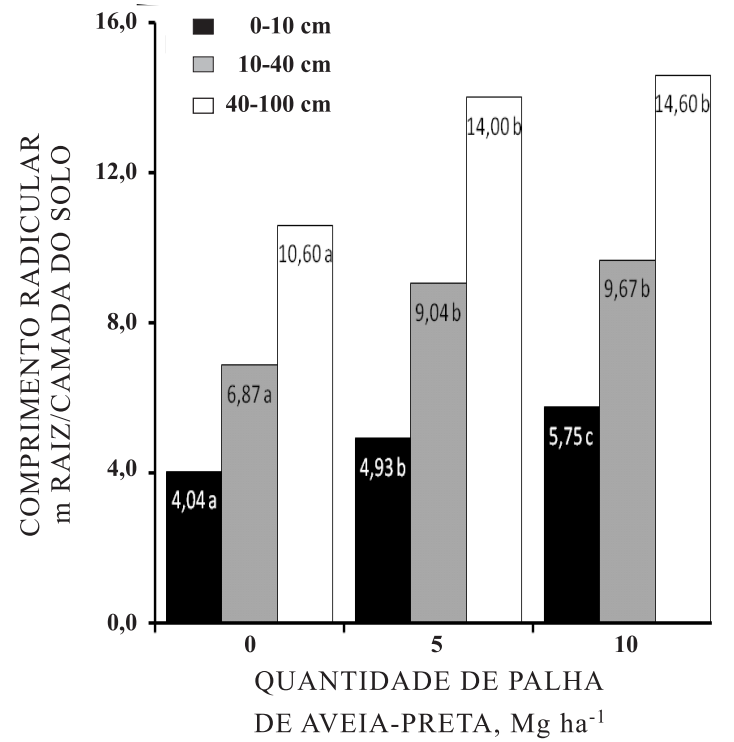

Figura 1. Comprimento radicular (média de 13 genótipos) nas camadas de 0-10, 10-40 e 40$100 \mathrm{~cm}$, alterado pela quantidade de palha de aveia-preta na superfície após seis anos de plantio direto. As letras inseridas nas barras verticais representam a comparação das médias pelo teste de Tukey a $5 \%$. Média dos dois anos agrícolas (2001/02 e 2002/03). de consolidação do sistema (acima de 10 anos) ocorre o maior acúmulo de palha associado ao acréscimo de C-resultando no aumento da CTC, a imobilização de $\mathrm{N}$ é menor do que a mineralização, além de haver maior ciclagem de nutrientes (Sá et al., 2004). Dessa forma, a adição de maior quantidade de palha na fase inicial de estabelecimento do SPD é mais impactante do que num sistema já consolidado. Além disso, a proteção do solo com a palha - pela sua ação como barreira física - também atuou na redução da amplitude térmica, possibilitando maior crescimento radicular na camada superficial.

O efeito físico da cobertura do solo na redução da evaporação da água do solo e da amplitude térmica proporciona ambiente favorável ao crescimento abundante de raízes terciárias. Essas raízes caracterizamse por uma meia-vida curta e são altamente sensíveis a temperaturas superiores a $36{ }^{\circ} \mathrm{C}$. Em geral, não possuem camada espessa de suberina e têm elevada afinidade na absorção de nutrientes (Fancelli \& Dourado-Neto, 2000). Outros fatores também podem estar atuando para esse aumento linear, como: (a) na camada superficial ocorre aumento da matéria orgânica do solo e da fertilidade, proporcionando maior aporte de nutrientes para a absorção pelas raízes (Sá, 1999; Sá \& Lal, 2009); (b) as primeiras raízes nodais encontram o ambiente favorável - maior disponibilidade de água e temperatura mais amena - para absorção de Ca e acúmulo na coifa, proporcionando maior proliferação de raízes. A maior concentração de $\mathrm{Ca}$ na coifa irá estimular maior crescimento radicular em profundidade; e (c) a liberação de compostos orgânicos oriundos da decomposição dos resíduos culturais tem sido citada como estimuladora da rizosfera e do crescimento da raiz devido à formação de complexos de ácidos orgânicos com íons de Al. É também conhecido o efeito de compostos orgânicos hidrossolúveis, oriundos da decomposição do material orgânico, no deslocamento de bases trocáveis, em especial do cálcio, resultando na melhoria do ambiente radicular em profundidade (Franchini et al., 1999; Ziglio et al., 1999). Ao mesmo tempo, esses efeitos 
parecem estender-se no perfil do solo, resultando na capacidade que a planta terá para a absorção de água. Conforme ocorreu o aumento da quantidade de palha na superfície do solo, a distribuição radicular foi mais uniforme em profundidade.

Nas camadas de 10-40 e 40-100 cm, a resposta do comprimento radicular à quantidade da palha foi significativa para a adição de $5,0 \mathrm{Mg} \mathrm{ha}^{-1}$ de palha e não apresentou diferença para a de $10 \mathrm{Mg} \mathrm{ha}^{-1}$, cujo ganho em relação ao tratamento sem palha foi de $31 \mathrm{e}$ $33 \%$, respectivamente. O aumento do sistema radicular em profundidade proporcionará maior capacidade das plantas em manter o suprimento adequado de água e nutrientes em períodos de estiagem. Essa afirmação é de grande importância para regiões com elevadas temperaturas e ocorrência de veranicos durante o ciclo de crescimento e desenvolvimento do milho. Apesar do maior crescimento radicular na camada de $0-10 \mathrm{~cm}$, o ganho relativo (em percentagem) foi bem distribuído ao longo do perfil nos dois tratamentos com palha (Figura 1). Igualmente, o ganho relativo no tratamento com a maior quantidade de palha na superfície quase duplicou na camada até $20 \mathrm{~cm}$ em relação ao tratamento com 5,0 $\mathrm{Mg} \mathrm{ha}^{-1}$ de palha (Figura 2). Outrossim, o ganho relativo foi superior no tratamento com 10,0 $\mathrm{Mg} \mathrm{ha}^{-1}$ em todas as camadas abaixo de $50 \mathrm{~cm}$ de profundidade.

O ganho relativo (média para todas as camadas amostradas) foi de 31,3 e 41,4\% para os tratamentos com 5,0 e 10,0 $\mathrm{Mg} \mathrm{ha}^{-1}$, respectivamente, em relação ao tratamento sem palha. O tratamento com a maior quantidade de palha na superfície promoveu o maior crescimento radicular abaixo de $50 \mathrm{~cm}$.

$\%$ DE GANHO NO COMPRIMENTO RADICULAR

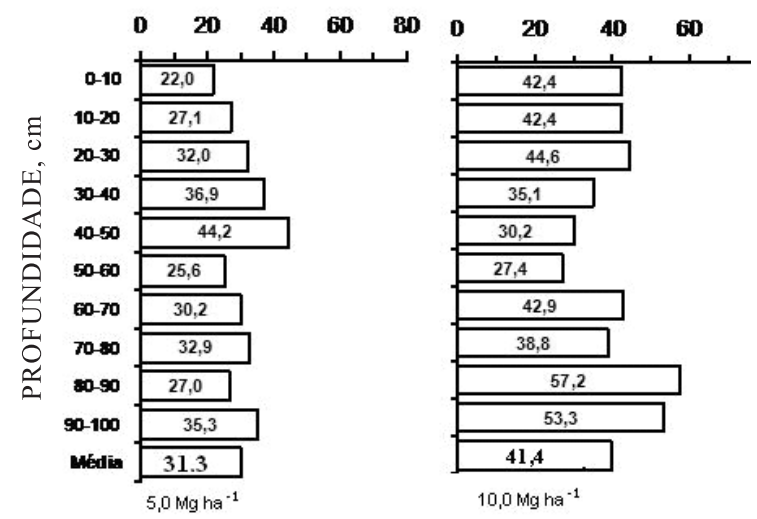

Figura 2. Percentagem de ganho no comprimento radicular (média de 13 genótipos) em cada camada amostrada nos tratamentos com 5,0 e $10,0 \mathrm{Mg} \mathrm{ha}^{-1}$ de palha, comparado ao tratamento sem palha. Os números inseridos nas barras horizontais representam a percentagem do ganho relativo. Média dos dois anos agrícolas (2001/02 e 2002/03).
O comprimento radicular dos genótipos AG 6018, AG 9020, DKB 350, MTC 955 e DKB 909 mostrou incrementos significativos com os tratamentos de palha, comparado ao tratamento sem palha (Quadro 3). Isso ocorreu provavelmente por se tratar de híbridos com alto desempenho no plantio direto, devido à maior adaptação ao efeito isolante que a palha promove ao solo, resultando em menor oscilação da temperatura na camada superficial, estimulando o crescimento radicular; como consequência, a manutenção da palha na superfície proporciona maior estabilidade a esses genótipos (Ferreira et al., 2009; Agroceres, 2010). Esses autores reportaram resultados semelhantes e atribuíram o maior incremento no comprimento radicular do genótipo AG 6018 à quantidade de 5,0 $\mathrm{Mg} \mathrm{ha}^{-1}$ de palha. A seleção de genótipos com maior habilidade em explorar o perfil do solo modificado pela adoção do sistema plantio direto, associado ao aporte e à manutenção dos resíduos culturais, será de grande valia para definir a melhor estratégia de uso e manejo. Os genótipos com maior capacidade de crescimento radicular nesses ambientes terão maior capacidade de tolerância a períodos secos e maior capacidade de extração de nutrientes.

A amplitude de resposta entre os genótipos foi ainda maior quando se realizou a estratificação do comprimento radicular em três camadas $(0-10,10-$ 40 e $40-100 \mathrm{~cm})$. Na camada de $0-10 \mathrm{~cm}$, a variação foi maior e diferenciou os genótipos com maior capacidade de adaptação ao SPD. Em regiões de altitude acima de $800 \mathrm{~m}$, com temperaturas mais amenas, o arranque e o estabelecimento da planta são de suma importância para expressar o potencial de produção. Nessas regiões, a taxa de decomposição da

Quadro 3. Comprimento radicular $\left(\mathrm{m} \mathrm{m}^{-2}\right)$ em função da interação quantidade de palha $\mathrm{x}$ genótipo, em um Latossolo Vermelho distrófico após seis anos de plantio direto ${ }^{(1)}$

\begin{tabular}{|c|c|c|c|}
\hline \multirow{2}{*}{ Genótipo } & \multicolumn{3}{|c|}{ Quantidade de palha $\left(\mathrm{Mg} \mathrm{ha}^{-1}\right)$} \\
\hline & $\mathbf{0}$ & 5 & 10 \\
\hline & \multicolumn{3}{|c|}{ Comprimento radicular $\left(\mathrm{m} \mathrm{m}^{-2}\right)$} \\
\hline DKB 212 & $21,12 \mathrm{Aa}$ & $25,85 \mathrm{Aa}$ & $31,87 \mathrm{Aa}$ \\
\hline DKB 214 & $22,20 \mathrm{Aa}$ & $28,44 \mathrm{Aa}$ & $32,68 \mathrm{Aa}$ \\
\hline DKB 215 & $21,30 \mathrm{Aa}$ & $26,72 \mathrm{Aa}$ & $28,06 \mathrm{Aa}$ \\
\hline AG 6018 & $19,22 \mathrm{Ab}$ & $34,45 \mathrm{Aa}$ & $32,18 \mathrm{Aa}$ \\
\hline AG 9020 & $19,74 \mathrm{Ab}$ & $25,53 \mathrm{Aa}$ & $25,13 \mathrm{Aa}$ \\
\hline DKB 350 & $19,60 \mathrm{Ac}$ & $27,65 \mathrm{Aab}$ & $34,51 \mathrm{Aa}$ \\
\hline DKB 747 & $20,59 \mathrm{Aa}$ & $25,73 \mathrm{Aa}$ & $31,72 \mathrm{Aa}$ \\
\hline MTC 907 & $23,88 \mathrm{Aa}$ & $28,11 \mathrm{Aa}$ & $29,98 \mathrm{Aa}$ \\
\hline MTC 955 & $22,26 \mathrm{Ab}$ & $32,59 \mathrm{Aa}$ & $28,45 \mathrm{Aa}$ \\
\hline DKB 909 & $23,00 \mathrm{Ab}$ & $32,10 \mathrm{Aa}$ & $34,93 \mathrm{Aa}$ \\
\hline EX 1104 & $23,94 \mathrm{Aa}$ & $26,66 \mathrm{Aa}$ & $32,14 \mathrm{Aa}$ \\
\hline EX 3308 & $19,69 \mathrm{Aa}$ & $22,96 \mathrm{Aa}$ & $23,86 \mathrm{Aa}$ \\
\hline EX 1108 & $19,44 \mathrm{Aa}$ & $28,20 \mathrm{Aa}$ & $23,17 \mathrm{Aa}$ \\
\hline
\end{tabular}

(1) Médias com letras iguais, maiúsculas nas colunas e minúsculas nas linhas, não diferem entre si pelo teste de Tukey a $5 \%$. Média dos dois anos agrícolas (2001/02 e 2002/03). 
aveia-preta é mais lenta na fase inicial de crescimento do milho. Além disso, a relação C:N mais elevada dos resíduos de aveia-preta estimula a reutilização do $\mathrm{N}$ mineralizado, provocando a sua imobilização na biomassa microbiana; consequentemente, ocorrerá um déficit de $\mathrm{N}$ no solo que coincidirá com a fase inicial de crescimento do milho (Ferreira et al., 2009). Por esse motivo, a escolha de genótipos com maior capacidade de desenvolvimento radicular no SPD, com elevado aporte de palha, será uma ferramenta importante para melhor exploração dos recursos nutricionais e hídricos do solo e obtenção de maiores rendimentos, sobretudo em anos de estiagem, durante o desenvolvimento da cultura do milho.

\section{Produção de grãos alterada pela quantidade de palha}

A produtividade média geral dos experimentos (média dos anos agrícolas 2001/02 e 2002/03) foi de $12.587 \mathrm{~kg} \mathrm{ha}^{-1}$. Quando comparado o efeito da quantidade de palha sobre a média dos 13 genótipos por tratamento, não se observaram diferenças significativas entre si (Quadro 4). Em contraste, a comparação entre genótipos dentro de cada tratamento (quantidade de palha) revelou diferenças significativas, indicando o comportamento diferenciado de genótipos em relação à quantidade de palha na superfície (Quadro 4).

O genótipo DKB 215 apresentou aumento significativo na produtividade com a adição de maior quantidade de palha (Quadro 4). Já o genótipo AG 6018, assim como os demais, não mostraram aumento

Quadro 4. Produtividade ( $\left.\mathrm{kg} \mathrm{ha}^{-1}\right)$ em função da interação quantidade de palha $\mathrm{x}$ genótipo, em um Latossolo Vermelho distrófico após seis anos de plantio direto ${ }^{(1)}$

\begin{tabular}{lccc}
\hline \multirow{4}{*}{ Genótipo } & \multicolumn{3}{c}{ Quantidade de palha $\left(\mathbf{M g ~ h a}^{-\mathbf{1}}\right)$} \\
\cline { 2 - 4 } & \multicolumn{4}{c}{$\mathbf{5 , 0}$} & $\mathbf{1 0 , 0}$ \\
\hline & Produtividade $\left(\mathrm{kg} \mathrm{ha}^{-1}\right)$ \\
DKB 212 & $12510 \mathrm{Aba}$ & $11675 \mathrm{Aa}$ & $11441 \mathrm{Aa}$ \\
DKB 214 & $12350 \mathrm{Aba}$ & $12818 \mathrm{Aa}$ & $12239 \mathrm{Aa}$ \\
DKB 215 & $8211 \mathrm{Bb}$ & $11896 \mathrm{Aa}$ & $11568 \mathrm{Aa}$ \\
AG 6018 & $12473 \mathrm{Aba}$ & $13046 \mathrm{Aa}$ & $13082 \mathrm{Aa}$ \\
AG 9020 & $11014 \mathrm{Aba}$ & $11428 \mathrm{Aa}$ & $12072 \mathrm{Aa}$ \\
DKB 350 & $11453 \mathrm{Aba}$ & $12005 \mathrm{Aa}$ & $12761 \mathrm{Aa}$ \\
DKB 747 & $11375 \mathrm{Aba}$ & $12210 \mathrm{Aa}$ & $11477 \mathrm{Aa}$ \\
MTC 907 & $12996 \mathrm{Aa}$ & $13232 \mathrm{Aa}$ & $12611 \mathrm{Aa}$ \\
MTC 955 & $12516 \mathrm{Aba}$ & $12877 \mathrm{Aa}$ & $12398 \mathrm{Aa}$ \\
DKB 909 & $12426 \mathrm{Aba}$ & $12372 \mathrm{Aa}$ & $13110 \mathrm{Aa}$ \\
EX 1104 & $13143 \mathrm{Aa}$ & $13278 \mathrm{Aa}$ & $12929 \mathrm{Aa}$ \\
EX 3308 & $13552 \mathrm{Aa}$ & $13829 \mathrm{Aa}$ & $14011 \mathrm{Aa}$ \\
EX 1108 & $14263 \mathrm{Aa}$ & $14437 \mathrm{Aa}$ & $13390 \mathrm{Aa}$ \\
\hline
\end{tabular}

(1) Médias com letras iguais, maiúsculas nas colunas e minúsculas nas linhas, não diferem entre si pelo teste de Tukey a $5 \%$. Média dos dois anos agrícolas (2001/02 e 2002/03). significativo na produtividade com a adição de palha, contradizendo dados obtidos por Ferreira et al. (2009), que observaram incremento na produtividade desse genótipo com a adição de palha. O genótipo DKB 215 destacou-se dos demais em produtividade possivelmente por apresentar ciclo mais longo se comparado ao dos demais. Isso permitiu ao genótipo maior aproveitamento do $\mathrm{N}$ mineralizado da palha (Quadro 5). De acordo com Sá (1999), a adição de elevada quantidade de palha de aveia-preta com relação $\mathrm{C} / \mathrm{N}$ entre 28 e 32 aumenta a biomassa microbiana, proporcionando a reutilização do $\mathrm{N}$ mineralizado da palha. Em consequência, há carência de $\mathrm{N}$ nos estádios iniciais de crescimento do milho e é possível que esse genótipo tenha maior sensibilidade e necessidade de maior quantidade de $\mathrm{N}$ para compensar esse efeito.

\section{Extração de nutrientes alterada pela quanti- dade de palha}

A quantidade de palha na superfície alterou a extração total de N, P e K (Figura 3). O aumento na quantidade de palha na superfície resultou na maior extração total de N, P e K e não alterou a extração total dos elementos $\mathrm{Ca}, \mathrm{Mg}$ e $\mathrm{S}$. A ordem do ganho relativo na extração total em relação à quantidade de palha (5,0 e 10,0 $\mathrm{Mg} \mathrm{ha}^{-1}$ ) foi $\mathrm{K}>\mathrm{P}>\mathrm{N}$, cujos valores foram de 30,4 e $47,1 \%, 17,6$ e $26,4 \%$ e 5,4 e $11,3 \%$, respectivamente. Essa ordem está coerente com a dinâmica desses elementos em solos sob plantio direto. De acordo com Sá (1999), a liberação de N e P pela decomposição dos resíduos culturais de aveia-preta é um processo lento e gradual, e a maior parte não coincide com o período de maior demanda pela planta. Daí a importância do manejo da adubação com esses elementos. Por outro lado, cerca de $80 \%$ do K dos resíduos culturais da aveia-preta é liberado durante o ciclo do milho (Holtz \& Sá, 1995).

Isso mostra que a planta de milho cultivada em SPD tende a extrair maior quantidade de nutrientes $(\mathrm{N}, \mathrm{P}$ e K), aumentando a qualidade nutricional dos grãos e também a qualidade (reciclagem) do resíduo da cultura após a retirada destes. Nesse caso, a grande quantidade de $\mathrm{K}$ liberado dos resíduos culturais, associada aos efeitos da palha sobre a superfície (dinâmica da água e redução da amplitude térmica) e ao maior crescimento radicular, resultou no aumento da extração total do elemento.

No tratamento sem palha, o genótipo AG 9020 apresentou menor extração total de $\mathrm{N}$ em relação aos genótipos DKB 350, MTC 907 e EX 1104. Isso ocorreu provavelmente pelo fato de esse genótipo apresentar um ciclo mais curto que o dos demais, resultando no menor aproveitamento do $\mathrm{N}$ mineralizado da palha. Os maiores incrementos na extração total de N com a adição de quantidades de palha na superfície do solo ocorreram para os genótipos DKB 215, AG 6018, DKB 350, DKB 747 e EX 3308 (Quadro 5). 

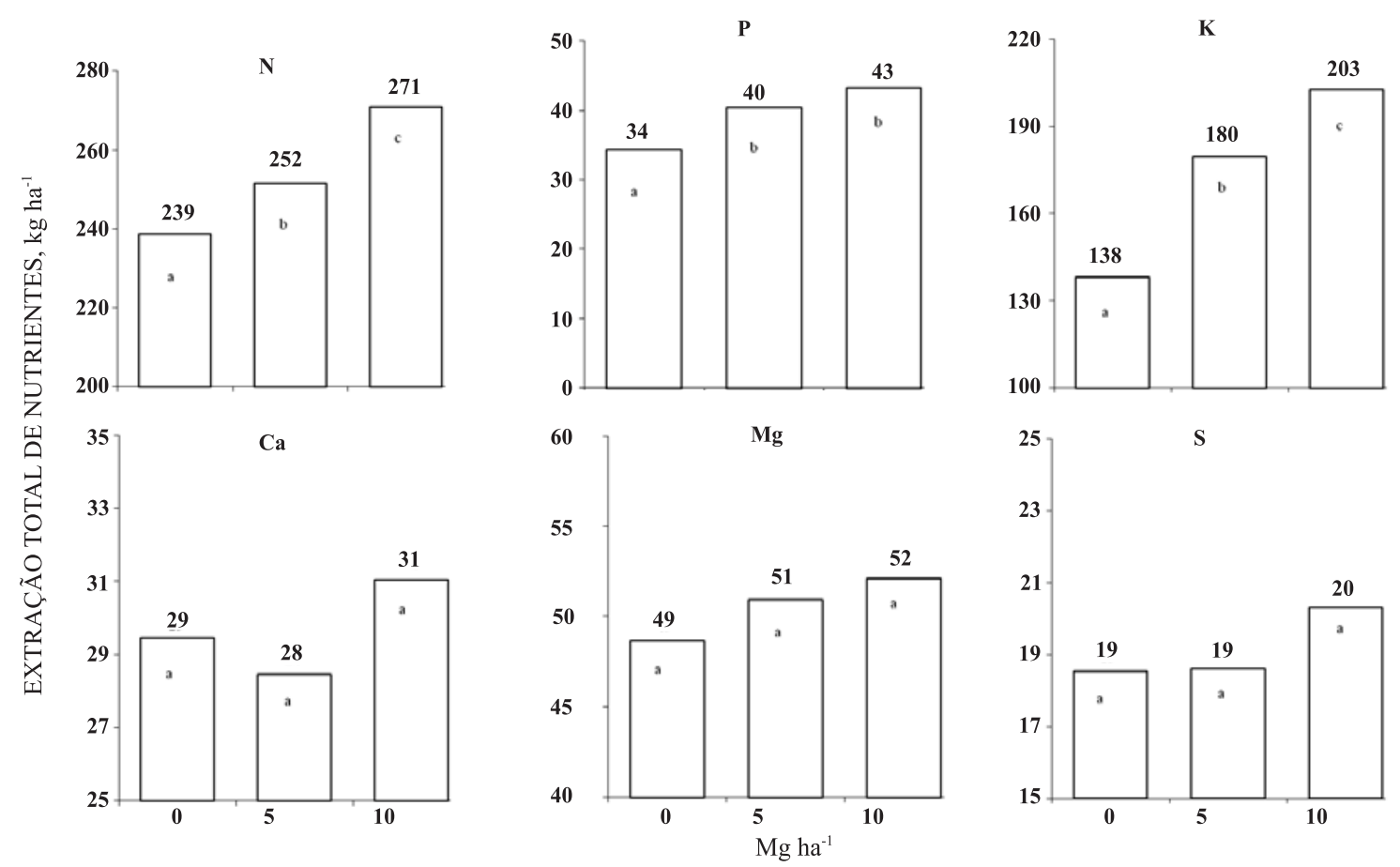

Figura 3. Extração total de N, P, K, Ca, Mg e S, em $\mathrm{kg} \mathrm{ha}^{-1}$, alteradas pela quantidade de palha na superfície. Comparação da média dos 13 genótipos entre os tratamentos sem e com palha na superfície, pelo teste de Tukey a $5 \%$. Letras minúsculas iguais nas barras verticais não diferem entre si estatisticamente. Média dos dois anos agrícolas (2001/02 e 2002/03).

Quadro 5. Extração total de nitrogênio $\left(\mathrm{kg} \mathrm{ha}^{-1}\right) \mathrm{em}$ função da interação quantidade de palha $x$ genótipo, em um Latossolo Vermelho distrófico após seis anos de plantio direto ${ }^{(1)}$

\begin{tabular}{|c|c|c|c|}
\hline \multirow{2}{*}{ Genótipo } & \multicolumn{3}{|c|}{ Quantidade de palha $\left(\mathrm{Mg} \mathrm{ha}^{-1}\right)$} \\
\hline & $\mathbf{0}$ & 5 & 10 \\
\hline & \multicolumn{3}{|c|}{ Nitrogênio $\left(\mathrm{kg} \mathrm{ha}^{-1}\right)$} \\
\hline DKB 212 & $234,17 \mathrm{ABa}$ & $247,80 \mathrm{ABCa}$ & $247,67 \mathrm{ABa}$ \\
\hline DKB 214 & $228,07 \mathrm{ABa}$ & $239,37 \mathrm{ABCa}$ & $269,23 \mathrm{ABa}$ \\
\hline DKB 215 & $238,73 \mathrm{ABb}$ & $237,70 \mathrm{ABCb}$ & $287,73 \mathrm{Aa}$ \\
\hline AG 6018 & $221,77 \mathrm{ABb}$ & $226,37 \mathrm{BCb}$ & 293,10 Aa \\
\hline AG 9020 & $188,43 \mathrm{Ba}$ & $216,73 \mathrm{Ca}$ & $219,77 \mathrm{Ba}$ \\
\hline DKB 350 & $254,40 \mathrm{Aab}$ & $250,23 \mathrm{ABCb}$ & $297,43 \mathrm{Aa}$ \\
\hline DKB 747 & $237,53 \mathrm{ABab}$ & $221,50 \mathrm{Cb}$ & $270,77 \mathrm{ABa}$ \\
\hline MTC 907 & $283,17 \mathrm{Aa}$ & $281,73 \mathrm{ABCa}$ & $268,17 \mathrm{ABa}$ \\
\hline MTC 955 & $237,67 \mathrm{ABb}$ & $290,53 \mathrm{ABa}$ & $256,63 \mathrm{ABab}$ \\
\hline DKB 909 & $247,77 \mathrm{Aba}$ & $237,63 \mathrm{ABCa}$ & $257,10 \mathrm{ABa}$ \\
\hline EX 1104 & $261,70 \mathrm{Aa}$ & $261,03 \mathrm{ABCa}$ & $291,47 \mathrm{Aa}$ \\
\hline EX 3308 & $241,07 \mathrm{ABb}$ & $297,30 \mathrm{Aa}$ & $285,83 \mathrm{Aab}$ \\
\hline EX 1108 & $229,46 \mathrm{Aba}$ & $269,53 \mathrm{ABCa}$ & $274,70 \mathrm{ABa}$ \\
\hline
\end{tabular}

(1) Médias com letras iguais, maiúsculas nas colunas e minúsculas nas linhas, não diferem entre si pelo teste de Tukey a $5 \%$. Média dos dois anos agrícolas (2001/2002 e 2002/2003).

O incremento da quantidade de palha na superfície do solo provocou aumento na altura de requeima das folhas pela deficiência de $\mathrm{N}$ em três épocas de amostragem a partir do florescimento pleno (Figura 4). Isso se explica pela imobilização do $\mathrm{N}$ mineral do solo $\left(\mathrm{NH}_{4}{ }^{+} \mathrm{e} \mathrm{NO}_{3}^{-}\right)$pelos microrganismos durante a decomposição do resíduo vegetal, na época de demanda de N pela planta (Sá et al., 2007; Ferreira et al., 2009).

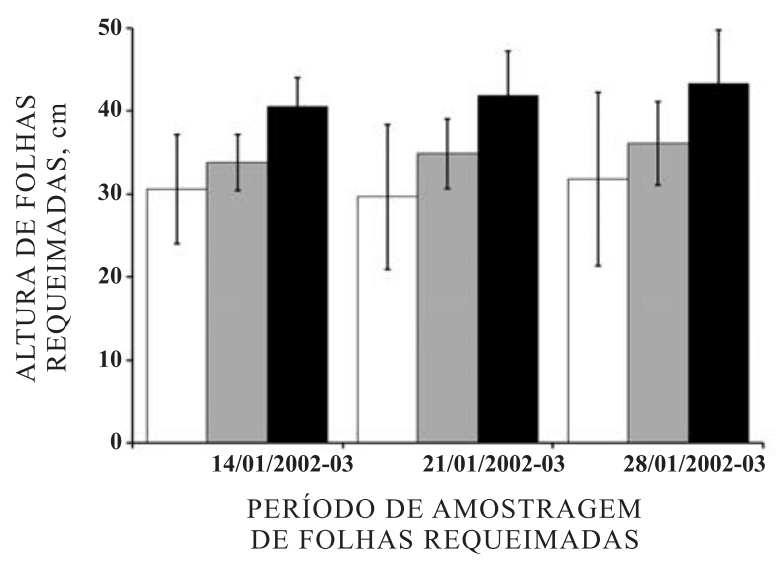

Figura 4. Altura de requeima, em razão da interação quantidade de palha $x$ genótipos, em um Latossolo Vermelho distrófico após seis anos de plantio direto (média dos 13 genótipos) em três épocas de amostragem, a partir do final do estádio de florescimento pleno. As demais datas foram durante o estádio de enchimento de grãos. As barras indicam o desvio-padrão em relação à média. $\square 0 \mathrm{Mg} \mathrm{ha}^{-1}$; $\square 5 \mathrm{Mg} \mathrm{ha}^{-1}$; $10 \mathrm{Mg} \mathrm{ha}^{-1}$. Média dos dois anos agrícolas (2001/02 e 2002/ 03). 
A evolução da altura de requeima (Figura 4) também indica a transferência de $\mathrm{N}$ das folhas mais velhas para os grãos e para as partes mais jovens, evidenciando ainda mais o efeito da quantidade de palha na deficiência de N. Recentemente, Ferreira et al. (2009) mostraram estreita relação entre quantidade de palha e resposta de genótipos a doses de $\mathrm{N}$. Outrossim, há genótipos que possuem maior eficiência na extração desse nutriente e possuem melhor desempenho quando há maior quantidade de palha na superfície. Assim, genótipos que apresentam maior crescimento radicular terão maior adaptação e desempenho em plantio direto em situações em que haja maior adição de palha da cultura antecessora.

\section{CONCLUSÕES}

1. Os genótipos de milho (AG 6018, AG 9020, DKB 350, MTC 955 e DKB 909) apresentam maior capacidade de crescimento radicular, em razão da adição de quantidades de palha de aveia-preta na superfície do solo, em sistema de plantio direto em fase inicial.

2. O desenvolvimento radicular das plantas de milho é beneficiado pela adição de palha tanto na camada superficial $(0-20 \mathrm{~cm})$ como na camada subsuperficial $(50-100 \mathrm{~cm})$ do solo.

3. O aumento na quantidade de palha na superfície do solo resultou em maior extração total de N, P e K, embora não tenha alterado a extração total dos elementos $\mathrm{Ca}, \mathrm{Mg}$ e S pela planta de milho.

\section{AGRADECIMENTOS}

À Monsanto do Brasil Ltda, pelo suporte financeiro; e à Universidade Estadual de Ponta Grossa (UEPG), pelo auxílio na condução do experimento, coleta e análise de amostras.

\section{LITERATURA CITADA}

AGROCERES. Híbridos Agroceres estarão presentes na Expodireto 2005 - Características. Disponivel em: < http:/ /www.agrosoft.org.br/agropag/9505.htm>. Acesso em: 08 fev. 2010 .

AITA, C. \& GIACOMINI, S.J. Decomposição e liberação de nitrogênio de resíduos culturais de plantas de cobertura de solo solteiras e consorciadas. R. Bras. Ci. Solo, 27:601612, 2003.

CAIRES, E.F.; BANZATTO, D.A. \& FONSECA, A.F. Calagem na superfície em sistema plantio direto. R. Bras. Ci. Solo, 24:161-169, 2000.
CAIRES, E.F.; FONSECA, A.F.; MENDES, J.; CHUEIRI, W.A. \& DRUGA, E.F. Produção de milho, trigo e soja em função das alterações das características químicas do solo pela aplicação de calcário e gesso na superfície, em sistema de plantio direto. R. Bras. Ci. Solo, 23:315-327, 1999.

COELHO, A.M. \& FRANÇA, G.E. Nutrição e adubação: Seja doutor do seu milho. Piracicaba, Potafos, 1995. (Arquivo do Agrônomo Potafos, 2)

CRESTANA, S.; GUIMARÃES, M.F.; JORGE, L.A.C.; RALISCH, R.; TOZZI, C.L.; TORRE, A. \& VAZ, C.M.P. Avaliação da distribuição de raízes no solo auxiliada por processamento de imagens digitais. R. Bras. Ci. Solo, 18:365-371, 1994.

CRUZ, C.C.; ALVARENGA, R.C.; NOVOTNY, E.H.; PEREIRA FILHO, I.A.; SANTANA, D.P.; PEREIRA, F.T.F. \& HERNANI, L.C. Sistema plantio direto. Embrapa Milho e Sorgo. Sistema de produção. Versão Eletrônica - 3.ed. Disponível em:< 25/jan/2007: http:// www.cnpms.embrapa.br/publicacoes/milho/ mandireto.htm>

EMPRESA BRASILEIRA DE PESQUISA AGROPECUÁRIA EMBRAPA. Centro Nacional de Pesquisa de Solos. Manual de métodos de análise de solo. 2.ed. Rio de Janeiro, 1997. 212p.

EMPRESA BRASILEIRA DE PESQUISA AGROPECUÁRIA EMBRAPA. Sistema brasileiro de classificação de solos. 2.ed. Rio de Janeiro, Embrapa Solos, 2006. 306p.

FANCELLI, A.L. \& DOURADO NETO, D. Produção de milho. Guaíba, Agropecuária, 2000. 360p.

FEDERAÇÃO BRASILEIRA DE PLANTIO DIRETO NA PALHA - FEBRAPDP. Evolução da área de plantio direto no Brasil - dados estatísticos. Disponível em: <http:// w w w . f e b r a p d p.org.br/a r quivo s/ BREvolucaoPD72a06.pdf>. Acesso em: 20 jan. 2008.

FERREIRA, A.O.; SÁ, J.C.M.; BRIEDIS, C. \& FIGUEIREDO, A.G. Desempenho de genótipos de milho cultivados com diferentes quantidades de palha de aveia-preta e doses de nitrogênio. Pesq. Agropec. Bras., 44:173-179, 2009.

FRANCHINI, J.C.; MIYAZAWA, M.; PAVAN, M.A. \& MALAVOLTA, E. Dinâmica de íons em solo ácido lixiviado com extratos de resíduos de adubos verdes e soluções puras de ácidos orgânicos. R. Bras. Ci. Solo, 34:2267-2276, 1999.

GAMA-RODRIGUES, A.C.; GAMA-RODRIGUES, E.F. \& BRITO, E.C. Decomposição e liberação de nutrientes de resíduos culturais de plantas de cobertura em Argissolo Vermelho-Amarelo na região noroeste fluminense (RJ). R. Bras. Ci. Solo, 31:1421-1428, 2007.

HOLTZ, G.P. \& SÁ, J.C.M. Resíduos culurais: Reciclagem de nutrientes e impacto na fertilidade do solo. In: SÁ, J.C.M., org. Curso sobre manejo do solo no sistema plantio direto. Castro, Fundação ABC, 1995. v.1. p.14-30.

MALAVOLTA, E.; VITTI, G.C. \& OLIVEIRA, S.A. Avaliação do estado nutricional das plantas: Princípios e aplicações. 2.ed. Piracicaba, POTAFOS, 1997. 319p. 
PAVAN, M.A.; BLOCH, M.F.; ZEMPULSKI, H.C.; MIYAZAWA, M. \& ZOCOLER, D.C. Manual de análise química do solo. Londrina, Instituto Agronômico do Paraná, 1991. 33p.

POLLMER, W.G.; EBERHARD, D.; KLEIN, D. \& DHILLON, B.S. Genetic control of nitrogen uptake and translocation in maize. Crop Sci., 19:82-86, 1979.

PURNOMO, E.; BLACK, A.S.; SMITH, C. \& CONYERS, M.K. The distribution of net nitrogen mineralization within surface soil. Field studies under a wheat crop. Austr. J. Soil Res., 38:129-140, 2000.

RODRIGUEZ, M.S.P. Varietal difference in maize in the uptake of nitrogen and translocation of the grain. Cornell, Cornell University, 1977. 167p. (Tese de Doutorado)

SÁ, J.C.M. Manejo da fertilidade do solo no plantio direto. Castro, Fundação ABC, 1993. 96p.

SÁ, J.C.M. Manejo da fertilidade do solo no plantio direto. In: SIQUEIRA, J.O.; MOREIRA, F.M.S.; LOPES, A.S.; GUILHERME, L.R.G.; FAQUIN, V.; FURTINI NETO, A.E. \& CARVALHO, J.G., eds. Soil fertility, soil biology, and plant nutrition interrelationships. Lavras, Universidade Federal de Lavras, Sociedade Brasileira de Ciência do Solo, 1999. p.267-320

SÁ, J.C.M. \& LAL, R. Stratification ratio of soil organic matter pools as an indicator of carbon sequestration in a tillage chronosequence on a Brazilian Oxisol. Soil Tillage Res. Res., 103:46-56, 2009 .

SÁ, J.C.M.; CERRI, C.C.; DICK, A.W.; LAL, R.; VENSKE FILHO, S.P.; PICCOLO, M.C. \& FEIGL, B.E. Soil organic matter dynamics and sequestration rates for a tillage chronosequence in a Brazilian Oxisol. Soil Sci. Soc. Am. J., 65:1476-1499, 2001.
SÁ, J.C.M.; CERRI, C.C.; PICCOLO, M.C.; FEIGL, B.E.; FORNARI, A.; Sá, M.F.M.; VENZKE FILHO, S.P.; SEGUY, L.; BOUZINAC, S. \& PAULLETI, V. O plantio direto como base do sistema de produção visando o sequestro de carbono. R. Plantio Direto, 84:45-61, 2004.

SÁ, J.C.M.; SANTOS, J.B.; CARDOSO, E.G.; SIUTA JUNIOR, D.; FERREIRA, C.F.; FERREIRA, A.O.; MASSINHAM, A. \& SÁ, M.F.M. Manejo de fertilizantes nitrogenados em sistemas de produção envolvendo os cultivos de soja / trigo e soja /milho safrinha no sistema plantio direto. In: YAMADA, T.; ABDALLA, S.R. \& VITTI, G.C., orgs. Nitrogênio e enxofre na agricultura brasileira. Piracicaba, International Plant Nutrition Institute, 2007. v.1. p.567649 .

SALL, J.; CREIGHTON, L. \& LEHMAN, A. JMP start statistics: A guide to statistics and data analysis using JMP and JMP IN software. 3.ed. Cary, Duxbury Press, 2005. 580p.

SIQUEIRA NETO, M.; VENZKE FILHO, S.P.; PICCOLO, M.C.; CERRI, C.E.P. \& CERRI, C.C. Rotação de culturas no sistema plantio direto em Tibagi (PR): I - Sequestro de carbono no solo. R. Bras. Ci. Solo, 33:1013-1022, 2009.

VASCONCELLOS, C.A.; FIGUEIREDO, A.P.H.D.; FRANÇA, G.E.; COELHO, A.M. \& BRESSAN, W. Manejo do solo e a atividade microbiana em Latossolo Vermelho-Escuro da região de Sete Lagoas, MG. Pesq. Agropec. Bras., 33:1897-1905, 1998.

ZIGLIO, C.; MIYAZAWA, M. \& PAVAN, M.A. Formas orgânicas e inorgânicas de mobilização do cálcio no solo. Braz. Arch. Biol. Technol., 42:257-262, 1999. 